\title{
ПРОМЫШЛЕННАЯ ПОЛИТИКА И ЕЁ ФИНАНСИРОВАНИЕ В ЕС
}

Аннотация. В статье рассмотрена современная концепция промышленной политики в Европейском союзе. Отмечено, что до сих пор не выработано чёткое единообразное определение промыиленной политики, поскольку она охватывает целый спектр различных направлений. Основу промышленной политики составляет статья Лиссабонского договора с четырьмя приоритетами, с учётом которых с 2017 г. действует её обновлённая концепция. Самыми важныли направлениями наднационального финансирования с точки зрения решения долгосрочных задач общеевропейского развития являются научные исследования и инновации.

Ключевые слова: Европейский союз, промышленная политика, финансирование, конкурентоспособность, цепочки создания стоимости, ключевые технологии.

В 2014 г. ещё в качестве кандидата на пост Председателя Европейской комиссии (ЕК) Ж.-К. Юнкер, выступая в Европейском парламенте, заявил о необходимости реиндустриализации Европейского союза (ЕС). Он призвал восстановить к 2020 г. до 20\% ВВП долю промышленности в ЕС, поскольку «рост в Европе не может быть основан лишь на услугах» ${ }^{1}$. Таким образом, впервые на таком высоком уровне было подчёркнуто, что вектор конкурентной борьбы в мировой экономике направлен на обрабатывающую промышленность, генерирующие технологии, которыми пользуются все остальные отрасли. Вот почему промышленная политика и её финансирование становятся предметом особого внимания в наднациональной политике Евросоюза.

Европейская промышленность находится в состоянии трансформации, дополнительный импульс которой придали последствия Великой рецессии 2008-2009 гг. В числе приоритетов - т.н. ключевые технологии (key enabling technologies), повышение ресурсоэффективности, новые модели предпринимательской деятельности, взаимопроникновение обрабатывающей промышленности и услуг.

Промышленная политика для Евросоюза - инструмент повышения конкурентоспособности, «двигатель инноваций, производительности труда и экспорта»². Основа современной промышленной политики - ст. 173 Договора о функционировании Европейского союза (ДФЕС), части Лиссабонского договора.

Несмотря на безусловную важность промышленной политики для динамичного долгосрочного развития ЕС, её определение и содержание несколько расплывчаты, что связано с

(C) Сидорова Елена Александровна - кандидат экономических наук, старший научный сотрудник Отдела глобальных экономических проблем и внешнеэкономической политики НИ ИМЭМО им. Е.М. Примакова РАН. Адрес: 117997, Россия, Москва, ул. Профсоюзная, д. 23; доцент кафедры международных экономических отношений и внешнеэкономических связей им. Н.Н. Ливенцева МГИМО МИД России. Aдрес: РФ, 119454, Москва, проспект Вернадского, 76. E-mail: yelena.sidorova@yahoo.com.

DOI: http://dx.doi.org/10.15211/vestnikieran620186

${ }^{1}$ A New Start for Europe: My Agenda for Jobs, Growth, Fairness and Democratic Change. Strasbourg, 2014,15 July. P. 7, 18. URL: https://ec.europa.eu/commission/sites/beta-political/files/juncker-political-guidelines-speech_en.pdf.

${ }^{2}$ Industrial policy. URL: https://ec.europa.eu/growth/industry/policy_en. 
рядом причин. Во-первых, до последнего времени при всей своей значимости тема промышленной политики не получала должного освещения, помимо узкоспециализированных периодических изданий. Во-вторых, промышленная политика в Евросоюзе сложна для анализа. На национальном уровне она всегда является объектом пристального внимания, вследствие значимости для общественных интересов (general interest). На наднациональном уровне чёткое институциональное определение промышленной политики отсутствует ${ }^{1}$.

В силу названных причин существуют два разных представления о том, что входит в сферу промышленной политики. В широком смысле промышленная политика означает разработку и координацию инициатив по повышению производительности труда и конкурентоспособности всей экономики и её отдельных отраслей (т.н. вертикальный подход) ${ }^{2}$. Этот подход предполагает широкий спектр государственных мер: к инструментам промышленной политики могут быть отнесены практически все направления экономической политики государства, включая социальные меры.

При узком определении промышленной политики она сводится к ограниченному набору мер в определённом числе отраслей для стимулирования будущего экономического роста (т.н. горизонтальный подход) $)^{3}$. Подобное определение также несовершенно, поскольку из него исключены такие важные направления промышленной политики, как например, стимулирование НИР или поддержка малых и средних предприятий (МСП). При этом на уровне Евросоюза ключевые отрасли функционируют и финансируются в соответствии с этим определением промышленной политики.

В новой Стратегии промышленной политики ЕС (2017) сделана попытка сочетать оба подхода. К вертикальным относятся специфические направления политики в стратегических секторах (космическая стратегия, Европейский оборонный фонд и пр.). К горизонтальным направлениям можно отнести цифровизацию, запуск современного интернет-стандарта $5 G$ на территории Евросоюза.

Основные цели современной промышленной политики ЕС включают:

- ускорение приспособления промышленности к структурным сдвигам;

- стимулирование благоприятного инвестиционного и предпринимательского климата, в особенности для МСП;

- поощрение межфирменной кооперации;

- содействие более эффективному использованию промышленного потенциала политики НИР и инноваций (см. бывш. ст. 157 Договора об учреждении Европейского сообщества, а ныне - ст. 173 ДФЕС $)^{4}$.

Как видно из перечня целей, в комплекс промышленной политики входит ряд смежных направлений (см. рисунок 1).

Очевидно, что Евросоюз на наднациональном уровне в силу ограничений объёма Общего бюджета ЕС (чуть более $1 \%$ ВНД ЕС) не может проводить промышленную политику и финансировать её с равной активностью по всем направлениям. Вот почему основное финансовое бремя несут национальные государства, а Евросоюз главное внимание обращает на научную, технологическую политику, инновации, а также координацию промышленной политики на различных уровнях.

\footnotetext{
${ }^{1}$ Industry and the European Union. Analysing Policies for Business. Ed. by M. Darmer, L. Kuyper. Cheltenham: Edward Elgar, 2000. P. 3-4.

${ }^{2}$ The Industrial Policy Debate. Edited by Ch. Johnson. San Francisco: Institute for Contemporary Studies, 1984. P. 8-9.

${ }_{4}^{3}$ См. подробнее: Industry and the European Union. Analysing Policies for Business. P. 6.

${ }^{4}$ Consolidated Version of the Treaty on the Functioning of the European Union // Official Journal of the European Union, 9.5.2008. C115/126; General principles of EU industrial policy. URL: http://www.europarl.europa.eu/factsheets/ en/sheet/61/general-principles-of-eu-industrial-policy.
}

Научно-аналитический вестник ИЕ РАН, 2018, №6 
Комплекс направлений промышленной политики ЕС

Рисунок 1

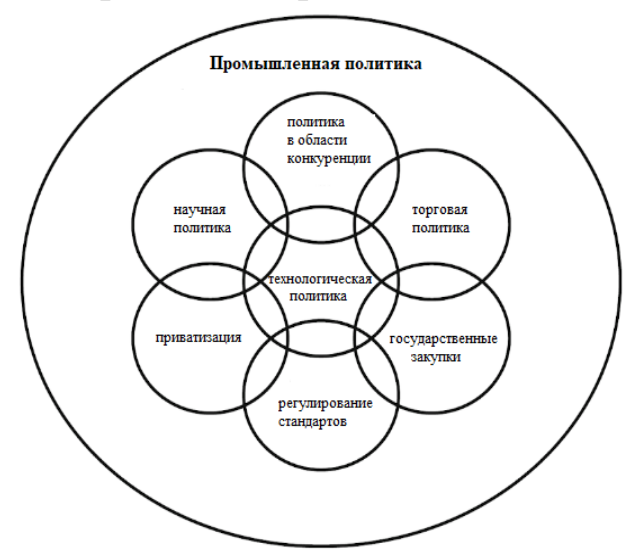

Источник: Sharp M. Science, Technology and Broad Industrial Policy: the co-evolution of policies at national, regional and European level. Sussex (UK), 2001, November. P. 24.

Наднациональная промышленная политика эффективно стимулирует взаимодействие между странами Европейского союза по указанным основным направлениям, особенно в сфере обмена технологиями. «Привлекательность ЕС... [как места размещения производств] будет определяться не низкими зарплатами, а инвестиционным потенциалом, финансированием исследований, разработок и инноваций - ИРИ (Research\&Development\&Innovation, $R \& D \& I){ }^{1}$, а также наличием высококвалифицированного человеческого капитала.

Инвестиции как главный двигатель инноваций по последним данным не дотягивают в Евросоюзе до целевого показателя в 3\% ВВП, предусмотренного Стратегией Европа-2020. В настоящее время средняя по ЕС цифра - примерно 2\%, но с существенными различиями по странам.

Таблица 1

Совокупные расходы на НИР по отдельным странам ЕС и мира (\% ВВП)

\begin{tabular}{|l|c|c|c|}
\hline Страны & 2000 & 2010 & 2016 \\
\hline ОЭСР & 2,11 & 2,28 & 2,33 \\
\hline ЕС-28 & 1,67 & 1,83 & 1,93 \\
\hline ФРГ & 2,39 & 2,71 & 2,93 \\
\hline Франция & 2,09 & 2,17 & 2,24 \\
\hline Италия & 1,00 & 1,22 & 1,28 \\
\hline Великобритания & 1,62 & 1,66 & 2,74 \\
\hline Финляндия & 3,24 & 3,72 & 1,00 \\
\hline Греция & $0,55^{*}$ & 0,59 & 0,48 \\
\hline Румыния & 0,36 & 0,45 & 0,96 \\
\hline Польша & 0,64 & 0,72 & 2,74 \\
\hline США & 2,62 & 2,74 & 3,14 \\
\hline Япония & 2,90 & 3,13 & 4,22 \\
\hline Южная Корея & 2,18 & 3,46 & 4,25 \\
\hline Израиль & 3,93 & 4,94 & 1,09 \\
\hline Россия & 0,97 & 1,04 & 2,10 \\
\hline Китай & 0,89 & 1,71 & \\
\hline
\end{tabular}

* 2001г.

Источник: Gross domestic spending on R\&D. OECD Data.

Как показывают данные ОЭСР (см. табл. 1), крупнейшие экономики Европейского союза пока не достигли целевого показателя, хотя ФРГ, судя по динамике, способна сделать это

\footnotetext{
${ }^{1}$ Presidency Note on «Reinforcing European Industrial Policy». Brussels: Council of the European Union, 2018,14 September. P. 3.
} 
в установленный срок до 2020 г. В абсолютных величинах для достижения целевого показателя ЕС-28 не хватает примерно 150 млрд евро в год. Доля затрат на науку в ВВП Китая уже больше, чем в ВВП ЕС. Евросоюз заявляет приоритетом стимулирование частных расходов в НИР с учётом ограниченных возможностей государственных вложений.

В 2017 г. были сформулированы основные пункты названной Стратегии развития промышленности ЕС (см. табл. 2). Слово «экосистема» в названии таблицы неслучайно: оно указывает не только на направления развития промышленной политики, но и на её субъекты, объекты воздействия промышленной политики, а также на инструменты её наднационального финансирования. Взаимосвязи в рамках «промышленной экосистемы» разветвлённые и сложные. Характерно и то, что сразу после финансовой составляющей следуют вопросы экологии, а уже потом - цифровизация и инновации.

Таблица 2

Промышленная экосистема

\begin{tabular}{|l|l|l|}
\hline Ключевые стороны & Направление политик & Воздействие \\
\hline ЕС & Инвестиции & Промышленность людям: навыки и образование, под- \\
Страны-члены & Сircular Есопоту & держка предпринимательства, признание квалификации. \\
Регионы & Низкоуглеродная экономика & Технологии для промышленности: ключевые техноло- \\
Промышленность & Единый рынок & гии, План Юнкера, Горизонт 2020, COSME, ESIF, IPCEI. \\
Социальные партнёры & Глобальный уровень & Промышленность регионов: умная специализация, коо- \\
& Регулирование & перация, трансформация старых промышленных пло- \\
& щифровизация & \\
& Щнновации & \\
\hline
\end{tabular}

Источник: A holistic strategy and a strong partnership in a new industrial age. Brussels, 2017. URL: https://ec.europa. eu/commission/news/new-industrial-policy-strategy-2017-sep-18_en.

Ключевые технологии с 2010 г. (после кризиса) составляют основу инноваций в промышленности (шесть направлений, включая микро- и наноэлектронику, промышленные биотехнологии и др.), что делает их основным элементом промышленной политики ЕС.

Что касается финансовой стороны вопроса, то план Юнкера (инвестиции для Европы) исчисляется сотнями миллиардов евро. Его основа - Европейский фонд стратегических инвестиций, который до конца 2020 г. планирует увеличить свою инвестиционную активность с 315 млрд до более 1,5 трлн евро с особым вниманием к проблемам экологии и изменения климата.

Горизонт 2020 - крупнейшая европейская программа финансирования ИРИ с общим объёмом более 80 млрд евро (2014-2020) для финансирования т.н. Инновационного союза флагманской инициативы Евросоюза. Программа для повышения конкурентоспособности предприятий COSME (Competitiveness of Enterprises and Small and Medium-sized Enterprises) располагает бюджетом свыше 1 млрд евро и рядом финансовых инструментов под управлением Европейского инвестиционного фонда.

Финансированием промышленной политики также заняты пять наднациональных фондов - Европейские структурные и инвестиционные фонды (European Structural \& Investment Funds, ESIF), в числе которых - Европейский фонд регионального развития. В сумме объём фондов на действующую Многолетнюю финансовую программу (2014-2020) превышает 450 млрд евро, в том числе на промышленную политику.

В 2018 г. учреждён Стратегический форум по важным проектам общеевропейского интереса (Important Projects of Common European Interest, IPCEI) в целях определения в промышленности стратегических цепочек создания стоимости и инвестиционных проектов в ключевых отраслях промышленности.

\footnotetext{
${ }^{1}$ Концепция «Экономики замкнутого цикла» внедрена Еврокомиссией с 2010 г. и включает снижение негативного экологического воздействия, сокращение издержек производства.
}

Научно-аналитический вестник ИЕ РАН, 2018, №6 
В 2016 г. Еврокомиссия обновила перечень ключевых отраслей промышленности, составляющих основу конкурентоспособности экономики стран ЕС. Сюда включены строительство, производство стали и бумаги, «зелёные» технологии, возобновляемые источники энергии (ВИЭ), обрабатывающая промышленность с морскими перевозками ${ }^{1}$. Впервые ЕК придала важное значение не только «прорывам» в промышленности, но и «охранительству», защите (defend, protect) своих позиций в мировой экономике, «обороне» пострадавших от структурных сдвигов регионов, рабочих мест.

В рамках Евросоюза с 2008 г. действует Инициатива ЕС по сырью (Raw materials Initiative, $R M I)$, которая, не будучи частью промышленной политики, имеет исключительно важное значение для обрабатывающей промышленности, поскольку «сырьё... лежит в основе цепочек создания стоимости», упомянутых ранее. Этот перечень пересматривается по меньшей мере раз в три года, и его версия 2017 г. содержит 27 видов сырья. Примечательно, что Франция (благодаря своим заморским территориям) - единственная в этом списке страна Европейского союза, которая является основным поставщиком стратегического металла гафния на рынок ЕС (71\%). Металл применяется в наиболее высокотехнологичных отраслях обрабатывающей промышленности ${ }^{2}$.

Серьёзность заявленных намерений Еврокомиссии, упомянутых её председателем ещё в 2014 г., подкреплена созданием с 2017 г. двух представительных площадок для обсуждения проблем промышленной политики и её финансирования. ЕК ежегодно перед весенним Советом ЕС проводит День промышленности с участием всех заинтересованных сторон. Обсуждаются достижения стран ЕС в этой области, состояние рабочих мест, внедрение инноваций, а также определение вызовов, на которые потребуется реакция всего Евросоюза.

В 2018 г. в рамках круглого стола «Промышленность 2030» (High Level Industrial Roundtable) была проведена вторая встреча на высоком уровне с участием представителей ЕС, национальных ведомств, промышленников, представителей общественности, профсоюзов и прочих заинтересованных игроков. Цель мероприятия - дать всестороннюю оценку действий Еврокомиссии в области промышленной политики.

Несмотря на свою сложность и неопределённость концепция промышленной политики активно развивается. Очередной прорыв произошёл в 2017 г. с появлением новой Стратегии промышленной политики, в которой отражены как проблемы, так и устремления ЕС. Хотя по ряду параметров промышленная политика стран Европейского союза не укладываются в намеченные сроки, к заслугам Ж.-К. Юнкера можно отнести стабилизацию доли обрабатывающей промышленности в ВВП и её выход на повышательную траекторию.

\section{Список литературы / References}

A holistic strategy and a strong partnership in a new industrial age. Brussels, 2017. URL: https://ec.europa.eu/commission/news/new-industrial-policy-strategy-2017-sep-18_en.

A New Start for Europe: My Agenda for Jobs, Growth, Fairness and Democratic Change. Strasbourg, 2014, 15 July. 37 p. URL: https://ec.europa.eu/commission/sites/beta-political/files/junckerpolitical-guidelines-speech_en.pdf.

Communication from the Commission to the European Parliament, the Council, the European Economic and Social Committee and the Committee of the Regions on the 2017 list of Critical Raw

\footnotetext{
${ }_{2}^{1}$ Making Europe's industry stronger: Key initiatives / New Industrial Policy Strategy. European Commission, 2017. P. 1.

${ }^{2}$ Communication from the Commission to the European Parliament, the Council, the European Economic and Social Committee and the Committee of the Regions on the 2017 list of Critical Raw Materials for the EU. Brussels, 13.9.2017. P. 3, 5.
} 
Materials for the EU. Brussels, 13.9.2017.

Consolidated Version of the Treaty on the Functioning of the European Union // Official Journal of the European Union, 9.5.2008. 199 p. URL: https://eur-lex.europa.eu/resource.html?uri=cellar: 41f89a28-1fc6-4c92-b1c8-03327d1b1ecc.0007.02/DOC_1\&format=PDF.

General principles of EU industrial policy. URL: http://www.europarl.europa.eu/factsheets/ en/sheet/61/general-principles-of-eu-industrial-policy.

Industrial policy. URL: https://ec.europa.eu/growth/industry/policy_en.

Industry and the European Union. Analysing Policies for Business. Ed. by M. Darmer, L. Kuyper. Cheltenham: Edward Elgar, 2000. 381 p.

The Industrial Policy Debate. Ed. by Ch. Johnson. San Francisco: Institute for Contemporary Studies, 1984, X + 275 p.

Making Europe's industry stronger: Key initiatives / New Industrial Policy Strategy. European Commission, 2017, 18 September. URL: https://ec.europa.eu/commission/news/new-industrialpolicy-strategy-2017-sep-18_en.

Presidency Note on «Reinforcing European Industrial Policy». Brussels: Council of the European Union, 2018, 14 September. 10 p. URL: https://www.consilium.europa.eu/media/36515/rethink ing-eu-indsutry_ai-and-robotics.pdf.

Sharp M. Science, Technology and Broad Industrial Policy: the co-evolution of policies at national, regional and European level. Sussex (UK), 2001, November.

\section{Industrial Policy and its financing in the European Union}

Author. Elena Sidorova, Candidate of Sciences (Economics), Senior Research Associate, Primakov National Research Institute of World Economy and International Relations, Russian Academy of Sciences. Address: 23, Profsoyuznaya str., Moscow, Russia, 117997; Assistant Professor, MGIMO University. Address: 76, Prospect Vernadskogo Moscow, Russia, 119454. E-mail: yelena.sidorova@yahoo.com.

Abstract. The article reviews the modern concept of industrial policy in the European Union. There is a lack of a clear uniform definition of industrial policy because it includes a whole variety of different areas. The fundamentals of the industrial policy contains an article of the Lisbon Treaty with four priorities. An updated concept of the EU industrial policy (operational since 2017) has taken these priorities into account. The most important areas of the EU supranational financing from the point of view of solving long-term problems of pan-European development are science, research and innovation.

Keywords: European Union, industrial policy, finances, competitiveness, value chains, key enabling technologies.

DOI: http://dx.doi.org/10.15211/vestnikieran620186 